\title{
Önlisans Turist Rehberliği Eğitimi Alan Öğrencile- rin Geleceğe Ait Düşüncelerinin Belirlenmesi: Mar- maris Turizm Meslek Yüksekokulu Örneği
}

DOI: $10.26466 /$ opus.395493

\section{Hande Akyurt Kurnaz ${ }^{*}$ - Alper Kurnaz ${ }^{* *}$}

* Öğr. Gör. Dr., Muğla Sıtkı Koçman Üniversitesi, Marmaris Turizm M.Y.O. Muğla / Türkiye

E-Posta: hande.akyurt.84@gmail.com

ORCID: 0000-0001-9712-6387

* Öğr. Gör. Dr., Muğla Sıtkı Koçman Üniversitesi, Marmaris Turizm M.Y.O. Muğla / Türkiye

E-Posta: alperkurnaz@gmail.com

ORCID: $\underline{0000-0001-5288-0706}$

\section{Öz}

Turizm sektöründe yer alan önemli paydaşlardan biri profesyonel turist rehberleridir. Profesyonel turist rehberleri ülkelerin tanıtım ve pazarlanmasında önemli rollere sahiptir. Türkiye'de turist rehberliği eğitimi basamaklı bir süreçten oluşmaktadır. Turist rehberliği eğitim sürecinin sona ermesiyle rehber adaylarım birçok aşama beklemektedir. Bu aşamaları sonucunda profesyonel turist rehberi olma hakkı kazanılmaktadır. Araştırmanın konusu önlisans turist rehberleriği eğitimi alan öğrencilerin gelecek ile ilgili düşünceleridir. Bu araştırma kapsamında detaylı bir alan yazın taraması yapılmıştır. Araştırmanın amacı önlisans turist rehberliği eğitimi alan öğrencilerinin geleceğe ait bakış açılarının tespit edilmesidir. Ayrıca almış oldukları eğitim ile ilgili de sorular yöneltilmiştir. Araştırmaya Marmaris Turizm Meslek Yüksekokulu Turist Rehberliği programı öğrencileri katılmıştır. Kolayda örnekleme yöntemi tercih edilmiştir. Çalışma verileri nicel veri toplama yöntemlerinden anket yöntemi ile elde edilmiştir. Anket soruları ulusal literatür derlenerek oluşturulmuştur. Ayrica araştırmanın sonucunda, turist rehberliği öğrencilerinin sevdiği bölümü okudukları ve gelecek kaygılarının düşük bir seviyede olduğu tespit edilmiştir. Ayrıca akademik kariyere odaklı oldukları tespit edilmiştir.

Anahtar Kelimeler: Eğitim Memnuniyeti, Öğrenci Kaygısı, Turist Rehberliği, Marmaris

OPUS (c) Uluslararası Toplum Araştırmaları Dergisi-International Journal of Society Researches ISSN:2528-9527 E-ISSN : 2528-9535

http://opusjournal.net 


\title{
A Research on Determining Future Thinking of the Students in Tourist Guidance Education in Associate Degree
}

\begin{abstract}
One of the key stakeholders involved in the tourism sector is professional tourist guides. Professional tourist guides have important roles in promoting and marketing countries. Tourist guide training in Turkey consists of a cascading process. Tourist guidance education in Turkey is a difficult process. After the training is over, many candidates are waiting for the guide candidates. As a result of these steps, the right to be a professional tourist guide is gained. The subject of the study is the future thinking of the students who are studying associate degree tourist guides. In this research, a detailed field search was done. The purpose of the research is to determine the perspectives for the future of the students who receive tourism guidance education in associate degree. They were also asked about the education they had received. Students of Marmaris Tourism Vocational School Tourism Guidance Program participated in the research. Sampling method is preferred. Quantitative data collection methods were collected by questionnaire method. Survey questions were compiled from national literature. As a result of there search, it was revealed that the students came in favor of the education and their future concerns were at a low level after the training started. They are also seen to be academic-focused.
\end{abstract}

Anahtar Kelimeler: The Educational Satisfaction Tourist Guidance, Marmaris

OPUS (c) Uluslararası Toplum Araştırmaları Dergisi-International Journal of Society Researches ISSN:2528-9527 E-ISSN : 2528-9535

http://opusjournal.net 


\section{Giriş}

Turizm endüstrisi özellikle son dönemlerde büyük ve farklı gelişmeler gösteren bir endüstri halini almıştır. Özellikle ekonomik girdileri açısından uluslararası turizm hareketleri önem kazanmıştır. Finansal olarak önemli bir endüstri olan turizmin eğitim yönünün de ağırlık kazanması gerekmektedir. Özellikle Türkiye turizm eğitimi açısından yeniliklere açık olmak ve turizm endüstrisinin eğitimli personel ihtiyacını sağlaması gerekmektedir (Baykal ve Şahin, 2015).

Eğitimli personel ihtiyacını temel ölçüde sağlayan önlisans programları incelendiğinde nicelik olarak artış olduğu gözlenmiştir. Özellikle eğitim kurumları kapsamında mesleklere ara eleman yetiştirilmesini sağlayan meslek yüksekokullarının önemi büyüktür (Üzümcü vd. 2015).

Bu çalışma Muğla Sıtkı Koçman Üniversitesi Marmaris Turizm Meslek Yüksekokulu Turist Rehberliği bölümünde okuyan öğrencilerin geleceğe ait düşüncelerinin belirlenmesi ve almış oldukları eğitim konusunda memnuniyetin durumunun tespit edilmesi amaciyla yapılmıştır.

\section{Profesyonel Turist Rehberi ve Türkiye Mevcut Durumu}

Turizm, sürekli gelişen bir ekonomik faktördür. Rekabet sürekliliğinin olduğu turizm pazarında, turizm paydaşlarının kalitesi önemlidir. Profesyonel kokartl rehberlik hizmetleri kaliteli turizm hizmetilerinin sağlanmasında temel rol oynamaktadır (Çetin ve Kızılırmak, 2015).

Rehber, profesyonel turizm çalışanıdır (Yarcan, 2007). Turistik cazibelerin birebir tanıtıldığ paket turlarda profesyonel turist rehberlerinin önemi büyüktür (Güzel vd. 2014). Turistler profesyonel turist rehberliği hizmetlerini yeterli ve kaliteli bir şekilde alabildiği ölçüde turizm tanıtımı da aynı düzeyde gelişebilmektedir (Batman, 2003).

Profesyonel turist rehberleri meslek hayatlarında çeşitli sorunlarla karşılaşmakta, bu sorunlar onların performanslarını etkileyebilmektedir. Bütün bu aşamalarla birlikte 22 Haziran 2012 tarihinde 6326 sayılı Turist Rehberliği Meslek Kanunu yasalaşarak yürürlüğe girmiştir (Zengin vd. 2017). 
Tablo 1: Rehberlerin Dillere Göre Dağılımı

\begin{tabular}{llll}
\hline Dil & Kişi Sayısı & Dil & Kişi Sayısı \\
\hline İngilizce & 6414 & İsveççe & 27 \\
Almanca & 1645 & Hirvatça & 25 \\
Fransızca & 1126 & Korece & 24 \\
İspanyolca & 686 & İbranice & 22 \\
Rusça & 663 & Macarca & 20 \\
Japonca & 581 & Romence & 19 \\
İtalyanca & 558 & Urduca & 9 \\
Portekizce & 348 & Danimarkaca & 8 \\
Arapça & 296 & Çekçe & 7 \\
Hollandaca & 237 & Ermenice & 7 \\
Bulgarca & 235 & Fince & 7 \\
Çince & 176 & Makedonca & 7 \\
Yunanca & 143 & Boşnakça & 6 \\
Endonezce & 62 & Slovakça & 3 \\
Lehçe & 48 & Hintçe & 2 \\
Sirpça & 45 & Gürcüce & 1 \\
Farsça & 34 & İzlandaca & 1 \\
Norveççe & 31 & Slovence & 1 \\
\hline
\end{tabular}

Kaynak: http://www.tureb.org.tr/tr/Page/Detail/91

Yabancı dillere göre turist rehberi sayıları incelendiğinde ise 6414 rehber ile İngilizce, 1645 rehber Almanca, 1126 rehber Fransızca olarak tespit edilmiştir.

Tablo 2: Turist Rehberlerinin Ülkesel-Bölgesel Dă̆ılımı

\begin{tabular}{llll}
\hline Durum & Kişi Sayısı & Durum & Kişi Sayısı \\
\hline Ülkesel & 9808 & Bölgesel & 435 \\
\hline
\end{tabular}

Kaynak: http://www.tureb.org.tr/tr/Page/Detail/91

Ülkesel rehberlerin bölgesel rehberlere oranla yüksek bir seviyede olduğu görülmüştür. Bu durumun sebeplerinden biri olarak iş hayatı açsindan ülkesel rehberlerin daha çok tercih edilmesi, tercih edilen paket turların özelliklerinden kaynaklandığı düşünülebilir. 
Önlisans Turist Rehberliği Eğitimi Alan Öğrencilerin Geleceğe Ait Düşüncelerinin Belirlenmesi: Marmaris Turizm Meslek Yüksekokulu Örneği

Tablo 3. Meslek Odalarına Göre Rehber Sayıları

\begin{tabular}{lccc}
\hline Meslek Odası & Kişi Sayısı & Eylemli & Eylemsiz \\
\hline İstanbul Turist Rehberleri Odası & 4419 & 2692 & 1727 \\
Antalya Turist Rehberleri Odası & 1674 & 1133 & 541 \\
İzmir Turist Rehberleri Odası & 1044 & 666 & 378 \\
Ankara Turist Rehberleri Odası & 724 & 357 & 367 \\
Nevşehir Turist Rehberleri Odası & 592 & 447 & 145 \\
Aydın Turist Rehberleri Odası & 580 & 461 & 119 \\
Muğla Turist Rehberleri Odası & 396 & 264 & 132 \\
Adana Bölgesel Turist Rehberleri Odası & 158 & 88 & 70 \\
Çanakkale Bölgesel Turist Rehberleri Odası & 147 & 104 & 43 \\
Gaziantep Bölgesel Turist Rehberleri Odası & 136 & 84 & 52 \\
Bursa Bölgesel Turist Rehberleri Odası & 115 & 78 & 37 \\
Şanlıurfa Bölgesel Turist Rehberleri Odası & 109 & 64 & 45 \\
Trabzon Bölgesel Turist Rehberleri Odası & 95 & 66 & 29 \\
Toplam & 10189 & 6504 & 3685 \\
\hline
\end{tabular}

Kaynak: http://www.tureb.org.tr/tr/Page/Detail/91

Bu bilgiler doğrultusunda Türkiye'de profesyonel turist rehberlerinin mevcut durumları incelendiğinde İstanbul Rehberler Odasına kayıtlı 4419, Antalya Rehberler Odasına kayıtlı 1674 ve İzmir Turist Rehberleri Odasına kayıtlı 1044 toplam rehber bulunmaktadır. Tüm odalara kayıtlı rehber sayısı 10189 kişi olup giderek bu sayı artmaktadır.

\section{Yöntem}

Araştırmanın evrenini Muğla Sıtkı Koçman Üniversitesi Marmaris Turizm Meslek Yüksekokulunda Turist Rehberliği eğitimi alan öğrenciler oluşturmuştur. Araştırmanın örneklem grubu kapsamında turist rehberliği öğrencilerine anket yöntemi uygulanmıştır. Toplam 169 anket dağıtılmış olup kullanılabilir anket sayısı 144'tür. Araştırmanın ölçeği Ünal ve Bayram (2015) ve Baltacı vd. (2012) yılında yapmış oldukları çalışmadan uyarlanmıştır. Katılımcıların ifadelere 3'lü Likert tipi ölçek kullanarak cevap vermeleri sağlanmıştır. Anketlerin tamamı örneklem grupla- 
rındaki öğrencilere birebir uygulanmıştır. Verilerin analizinde SPSS programı kullanılmıştır.

\section{Bulgular}

Araştırmaya katılan öğrencilerin demografik bilgilere ait yüzde ve frekans bulguları Tablo $4^{\prime}$ te sunulmuştur.

Araştırmaya katılan öğrencilerin cinsiyetlerin birbirine yakın olduğu tespit edilmiştir. Bu durumda turist rehberliği bölümünü tercih etme açısından cinsiyet farklılığının olmadığı görülmüştür. Genellikle 17-21 yaş aralığında olup, lise olarak Anadolu turizm meslek lisesi mezunu oldukları belirlenmiştir. Özellikle lise açısından turizm ile alakalı bir okuldan mezun oldukları tespit edilmiştir. Araştırmaya katılanların s1nıfları 1. Sınıf olarak belirlenmiş olup çoğunlukla normal öğretim okuyan öğrencilerin araştırma kapsamında olduğu incelenmiştir. Özellikle okulun Marmaris'te olmasından dolayı gelen öğrencilerin yoğun olarak Ege Bölgesi'nde yaşadı̆̆ı ve bölümü seçme nedeni olarak mesleği sevdikleri için tercih ettikleri tespit edilmiştir. Bu bağlamda bölüm tercihinde mesleğin durumu önemli bir etkendir.

Tablo 4: Demografik Bilgiler

\begin{tabular}{llll}
\hline & & $\mathbf{n}$ & $\mathbf{\%}$ \\
\hline \multirow{2}{*}{ Cinsiyet } & Erkek & 69 & 47,9 \\
& Kadın & 75 & 52,1 \\
Yaş & $17-21$ & 103 & 71,5 \\
& $22-26$ & 28 & 19,4 \\
& $26+$ & 13 & 9 \\
& Düz Lise & 26 & 18,1 \\
\multirow{4}{*}{ Lise } & Anadolu Lisesi & 22 & 15,3 \\
& Meslek Lisesi & 36 & 25 \\
& Anadolu Turizm Meslek Lisesi & 51 & 35,4 \\
& Diğer & 9 & 6,3 \\
\multirow{4}{*}{ Sinıf } & 1 & 86 & 59,7 \\
& 2 & 49 & 34 \\
Öğrenim & Noratma & 9 & 6,3 \\
Türüi & İkinci & 87 & 60,4 \\
\hline
\end{tabular}


Önlisans Turist Rehberliği Eğitimi Alan Öğrencilerin Geleceğe Ait Düşüncelerinin Belirlenmesi: Marmaris Turizm Meslek Yüksekokulu Örneği

\begin{tabular}{llll}
\hline & Ege & 92 & 63,9 \\
& Akdeniz & 16 & 11,1 \\
Gelinen & Marmara & 20 & 13,9 \\
Yer & İç Anadolu & 8 & 5,6 \\
& Karadeniz & 3 & 2,1 \\
& Doğu & 3 & 2,1 \\
& Güneydoğu & 2 & 1,4 \\
& Mesleği Seviyorum & 85 & 59 \\
\multirow{5}{*}{ Tercih } & Sinav Puanı & 12 & 8,3 \\
& Geçerli Meslek & 23 & 16 \\
& Başka Seçenek Yok & 4 & 2,8 \\
& Tavsiye & 20 & 13,9 \\
\hline
\end{tabular}

Demografik bilgilerin incelenmesinin ardından ölçekte yer alan ifadelerin dağılımları incelenmiş ve normal dağılıma sahip olduğu tespit edilmiştir. Skewness ve Kurtosis değerlerinin $+2,-2$ değerleri arasında olduğu incelenmiştir. Böylelikle normal dağılıma ait olan testler yardımı ile analizlerin devam etmesi sağlanmıştır.

Tablo 5: Memnuniyet Düzeylerinin Ortalamasının Belirlenmesi

\begin{tabular}{lll}
\hline İfade & X & S.S \\
\hline Sevmediğim Dersleri Okumakta Zorlanıyorum & 1,8889 &, 73960 \\
Dersler Çok Zor, Anlamadan Ezberlemek Zorunda Kalıyorum & 2,3125 &, 77069 \\
Haftalık Ders Programları İyi Hazırlanıyor & 1,8819 &, 81504 \\
Stajlardan Memnunum & 1,7778 &, 74275 \\
Turizm İle İlgili Derslerin Sayıca Yeterli Olduğunu & 1,8333 &, 82784 \\
Düşünüyorum & & \\
Almış Olduğum Eğitimden Memnunum & 1,6250 &, 77437 \\
Okulu Bırakmak İstiyorum & 2,6319 &, 68701 \\
Ekonomik Sebeplerden Öğrenimime Devam Edemeyeceğimden & 2,3264 &, 75568 \\
Korkuyorum & & \\
Mezun Olunca İş Bulamama İhtimali Beni Korkutuyor & 1,7986 &, 82428 \\
İleride Ailemi Geçindirememekten Korkuyorum & 2,0278 &, 86051 \\
Akademik Kariyer Yapmak Istiyorum & 1,6250 &, 80100 \\
Mezuniyet Sonrası Tam Olarak Ne Yapacağımı Bilmiyorum & 2,1111 &, 85371 \\
Mezuniyet Sonrası Turizmde Çalışmayı Düşünüyorum & 1,6389 &, 79870 \\
\hline
\end{tabular}

Katılımcıların vermiş oldukları cevaplar doğrultusunda memnuniyet düzeyleri incelendiğinde almış olduğu eğitimden memnun ve akademik 
kariyer odaklı oldukları ve turizm sektöründen çalışmayı düşündükleri tespit edilmiştir. Ayrıca mezun olduktan sonra iş bulamama ihtimalinin tedirgin ettiği görülmüştür. Genel olarak stajlardan memnun ve turizm ile ilgili derslerin nicelik açısından yeterli olduklarını belirtmişlerdir.

Tablo 6'ya göre, akademik kariyer yapmak istiyorum, mezuniyet sonrası turizmde çalışmayı düşünüyorum ve almış olduğum eğitimden memnunum ifadeleri yüksek katılım dereceleri arasında yer alırken, mezun olunca iş bulamama ihtimali beni korkutuyor ifadesi düşük katılım derecesi arasında yer almıştır. Genel olarak araştırmaya katılan öğrencilerin gelecek kaygılarının düşük olduğu, gelecek planlarının olduğu ve almış oldukları eğitimden memnun oldukları tespit edilmiştir.

Tablo 6: Memnuniyet Düzeylerine Ait Frekans ve Yüzde Değerleri

\begin{tabular}{|c|c|c|c|c|c|c|}
\hline İfade & Evet & & Belki & & Hay1 & \\
\hline & $\mathbf{n}$ & $\%$ & $\mathbf{n}$ & $\%$ & $\mathbf{n}$ & $\%$ \\
\hline $\begin{array}{l}\text { Sevmediğim Dersleri Okumakta } \\
\text { Zorlaniyorum }\end{array}$ & 48 & 33,3 & 64 & 44,4 & 32 & 22,2 \\
\hline $\begin{array}{l}\text { Dersler Çok Zor, Anlamadan } \\
\text { Ezberlemek Zorunda Kalıyorum }\end{array}$ & 25 & 18,8 & 45 & 31,3 & 72 & 50 \\
\hline $\begin{array}{l}\text { Haftalık Ders Programları İyi } \\
\text { Hazırlanıyor }\end{array}$ & 57 & 39,6 & 47 & 32,6 & 40 & 27,8 \\
\hline Stajlardan Memnunum & 59 & 41 & 58 & 40,3 & 27 & 18,8 \\
\hline $\begin{array}{l}\text { Turizm İle İlgili Derslerin Sayıca } \\
\text { Yeterli Olduğunu } \\
\text { Düșünüyorum }\end{array}$ & 62 & 43,8 & 42 & 29,2 & 39 & 27,1 \\
\hline $\begin{array}{l}\text { Almış Olduğum Eğitimden } \\
\text { Memnunum }\end{array}$ & 80 & 55,6 & 38 & 26,4 & 26 & 18,1 \\
\hline Okulu Bırakmak İstiyorum & 17 & 11,8 & 19 & 13,2 & 108 & 75 \\
\hline $\begin{array}{l}\text { Ekonomik Sebeplerden Öğren- } \\
\text { imime Devam Edemeyeceğim- } \\
\text { den Korkuyorum }\end{array}$ & 25 & 17,4 & 47 & 32,6 & 72 & 50 \\
\hline $\begin{array}{l}\text { Mezun Olunca İş Bulamama } \\
\text { İhtimali Beni Korkutuyor }\end{array}$ & 66 & 45,8 & 41 & 28,5 & 37 & 25,7 \\
\hline $\begin{array}{l}\text { İleride Ailemi Geçindi- } \\
\text { rememekten Korkuyorum }\end{array}$ & 51 & 35,4 & 38 & 26,4 & 55 & 38,2 \\
\hline $\begin{array}{l}\text { Akademik Kariyer Yapmak } \\
\text { İstiyorum }\end{array}$ & 83 & 57,6 & 32 & 22,2 & 29 & 20,1 \\
\hline $\begin{array}{l}\text { Mezuniyet Sonrası Tam Olarak } \\
\text { Ne Yapacağımı Bilmiyorum }\end{array}$ & 45 & 31,3 & 38 & 26,4 & 61 & 42,4 \\
\hline $\begin{array}{l}\text { Mezuniyet Sonrası Turizmde } \\
\text { Çalışmayı Düşünüyorum }\end{array}$ & 81 & 56,3 & 34 & 23,6 & 29 & 20,1 \\
\hline
\end{tabular}


Önlisans Turist Rehberliği Eğitimi Alan Öğrencilerin Geleceğe Ait Düşüncelerinin Belirlenmesi: Marmaris Turizm Meslek Yüksekokulu Örneği

\section{Sonuç ve Tartışma}

Marmaris Turizm Meslek Yüksekokulu Turist Rehberliği bölümünde okuyan öğrencilerin vermiş oldukları cevaplar doğrultusunda bazı temel sonuçlara ulaşılmıştır. Demografik bilgilerde cinsiyet açısından bir farklılı̆̆ın olmadığı, 17-21 yaş arasında, genellikle Ege bölgesinden gelen, turizm ile alakalı liseden mezun ve mesleği sevdikleri, çevrelerinden tavsiye edildiği ve geçerli bir meslek olarak düşündükleri için bölümü tercih ettikleri tespit edilmiştir.

Araştırmaya katılan öğrencilerin eğitim memnuniyeti açısından olumlu düşündükleri, geleceğe dair planlarının olduğu özellikle akademik kariyer konusunda hevesli oldukları, gelecek kaygılarının da düşük seviyelerde yer aldığ incelenmiştir.

Ünal ve Bayram (2015) araştırmasında öğrencilerin yarısından fazlasının okuduğu alanı severek tercih ettikleri ve çoğunun turizm meslek lisesi çıkışlı olduklarını tespit etmiştir. Bu bağlamda iki çalışmanın sonuçları birbirleri ile doğru orantılıdır. Böylelikle turist rehberliği ve turizm bölümlerini okuyan öğrencilerinin büyük bir kısmı alan olarak severek eğitim aldıkları incelenmiştir.

Baltacı vd. (2012) çalışmalarında öğrencilere mezun olduklarında turizm sektöründe çalışmayı düşünüp düşünmedikleri sorulmuş ve turizm sektöründe çalışmayı düşünmeyenler sayısal olarak az olduğu belirlemiştir. Bu sonuç doğrultusunda araştırma ile benzer sonuçların elde edildiği incelenmiştir. Ayrıca aynı çalışmada gelecek kaygı durumu bakımından daha karamsar oldukları incelenmiştir. Bu açıdan iki çalışma arasında fark bulunmuştur.

Sektöre yönelik kaygıların azaltılması veya mesleğin tanınabilirliğinin arttırılması konusunda bazı çalışmalar yapmak mümkündür. Örneğin, sektörden tanınmış profesyonel turist rehberler okullara davet edilip, öğrencilere meslek ile ilgili bilgilendirme yapılabilir (Şen Şahin ve Acun, 2016).

Gelecek çalışmalar açısından Marmaris Turizm Meslek Yüksekokulu kapsamında farklı bölümlere araştırmanın uygulanıp, bölümler arasındaki farklılıkların da belirlenerek karşılaştırma yapılabilir. Ayrıca farklı 
önlisans turist rehberliği bölümleri ile çalışmanın kapsamı genişletilip genel değerlendirmeler ortaya çıkarmak mümkündür.

\section{Kaynaklar}

Baltac1, F.; Üngüren, E.; Avsallı, H. ve Demirel, O. N. (2012). Turizm eğitimi alan öğrencilerin eğitim memnuniyetlerinin ve geleceğe yönelik bakış açılarının belirlenmesine yönelik bir araştırma. Uluslarararası Alanya İşletme Fakültesi Dergisi, 4(1), 17-25.

Batman, O. (2003). Türkiye'deki profesyonel turist rehberlerinin mesleki sorunlarına yönelik bir araştırma. Bilgi, 7(2), 117-134.

Baykal, D. ve Şahin, E. (2015). Türkiye'de turizm eğitimi veren meslek yüksekokullarının ders programlarına ilişkin bir içerik analizi. Elektronik Mesleki Gelişim ve Araştırmalar Dergisi, 2(3), 19-32.

Çetin, G. ve Kızılırmak, İ. (2015). Türk turizminde kokartlı turist rehberlerin mevcut durumunun analizi. Afyon Kocatepe Üniversitesi İktisadi ve İdari Bilimler Fakültesi Dergisi, 14(2), 307-318.

Güzel, F.Ö., Türker, A. ve Şahin, İ. (2014). Profesyonel turist rehberlerinin algıladıkları mesleki engelleri belirlemeye yönelik bir araştırma. Gazi Üniversitesi Turizm Fakültesi Dergisi, 2, 173-190.

Şen Şahin, S. ve Acun, A. (2016). Turizm rehberliği öğrencilerinin mesleğe yönelik tutumları. Gaziantep University Journal of Social Sciences, 15(2),563-580.

Ünal, İ. ve Bayram, A. T. (2015). Önlisans düzeyinde turizm eğitimi alan öğrencilerin memnuniyet düzeyine yönelik karşılaştırmalı bir araştırma. Akademik Sosyal Araştırmalar Dergisi, 3(10), 525-534.

Üzümcü Polat, T., Alyakut, Ö. ve Günsel, A. (2015). Turizm eğitimi alan öğrencilerin, mesleğin geleceğine ilişkin bakış açıları, Balıkesir Üniversitesi Sosyal Bilimler Enstitüsü Dergisi, 18(33), 179-199.

Yarcan, Ş. (2007). Profesyonel turist rehberliğinde mesleki etik üzerine kavramsal bir değerlendirme. Anatolia: Turizm Araştırmaları Dergisi, 18(1), 33-44.

Zengin, B., Eker, N. ve Erkol Bayram, G. (2017). Turist rehberliği meslek kanununun profesyonel turist rehberlerince değerlendirilmesi, Seyahat ve Otel İsletmeciliği Dergisi, 14(2), 142-156.

http://www.tureb.org.tr/tr/Page/Detail/91. Erişim Tarihi 14.02.2018 
Önlisans Turist Rehberliği Eğitimi Alan Öğrencilerin Geleceğe Ait Düşüncelerinin Belirlenmesi: Marmaris Turizm Meslek Yüksekokulu Örneği

\section{Kaynakça Bilgisi / Citation Information}

Akyurt-Kurnaz, H. ve Kurnaz A. (2018). Önlisans turist rehberliği eğitimi alan öğrencilerin geleceğe ait düşüncelerinin belirlenmesi: Marmaris turizm meslek yüksekokulu örneği. OPUS - Uluslararası Toplum Araştırmaları Dergisi, 8(Gençlik Araştırmaları Özel Sayısı), 237-247. 